\title{
Evaluation of post-earthquake loading capacity of steel reinforced retaining wall by displacement and/or loading controlled pullout test
}

\author{
Motoyuki Suzuki ${ }^{\text {i) }}$, Ryohei Asada ${ }^{\text {ii) }}$, Yoshinori Otani ${ }^{\text {iii) }}$ and Naoki Shimura ${ }^{\text {iv }}$ \\ i) Associate Professor, Graduate School of Science and Engineering, Yamaguchi University, 2-16-1, Tokiwadai, Ube 755-8611, Japan. \\ ii) Graduate Student, ditto \\ iii) Team Manager, Reinforced Earth Department, Hirose co., ltd., 4-1-13, Koto-ku Toyo, Tokyo 135-0016, Japan. \\ iv) Assistant Manager, Reinforced Earth Department, Hirose co., ltd., 4-1-13, Koto-ku Toyo, Tokyo 135-0016, Japan.
}

\begin{abstract}
Reinforced retaining walls were slightly damaged during recent Japanese earthquakes. Therefore, it is important to clarify the post-earthquake loading capacity of reinforced retaining walls to evaluate the safety, stability, and availability of damaged walls. Using displacement and/or loading-controlled pullout tests, we examined the pullout behaviour of a strip under constant pullout loading in a compacted soil layer that was subjected to various pullout histories. This paper evaluates the post-earthquake loading capacity of a steel reinforced retaining wall based on these test results. The primary conclusions are as follows: 1 ) when the pullout load did not exceed peak value, the resultant pullout displacement was only 3 to $6 \mathrm{~mm} ; 2$ ) the pullout behaviour of the strip was not significantly affected by the previous pullout; 3 ) unless the pullout load did not surpass peak or yield values in the relation between pullout load and displacement, even after the earthquake, the reinforced retaining wall maintained its loading capacity to some extent.
\end{abstract}

Keywords: reinforced earth wall, earthquake, loading capacity, degree of compaction, pullout test

\section{INTRODUCTION}

The steel reinforced soil retaining wall is one of the most widely used soil reinforcement methods in Japan because of its reliability and cost. As shown in Figure 1, the pullout resistance generated between reinforcement and soil results in sufficient equilibrium with active earth pressure to hold a retaining wall in place. Sandy soils are selected as fill material because they are among the most suitable materials, with sufficient frictional resistance to produce an attainable maximum interface pull resistance. This method has been used successfully for soil structures in Japan.

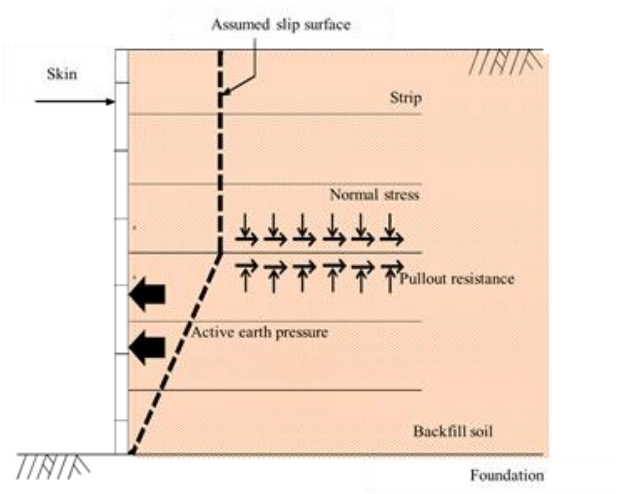

Figure 1. Schematic view of reinforced retaining soil wall.
Reinforced retaining walls such as Terre Armée exhibit excellent anti-earthquake resistance compared with other soil structures. However, certain reinforced retaining walls were slightly damaged in recent Japanese earthquakes as shown in Figure 2(Sahara, 2012). When a large earthquake occurs, an earth retaining wall may displace due to the decrease in pullout resistance between the soil and reinforcement, as well as the increase in active earth pressure of the backfill soil behind the wall. In the aftermath of this earthquake, the wall would remain in an unstable condition. Therefore, it is necessary to investigate residual pullout resistance in reinforced retaining walls with earthquake history. This implies that it is also important to understand postseismic responses of reinforced soil walls.

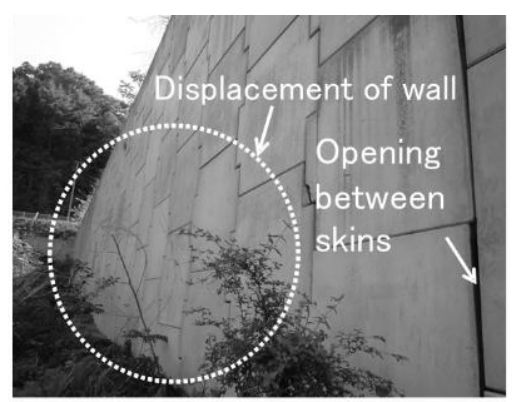

Figure 2. Case history of damaged wall after earthquake. 


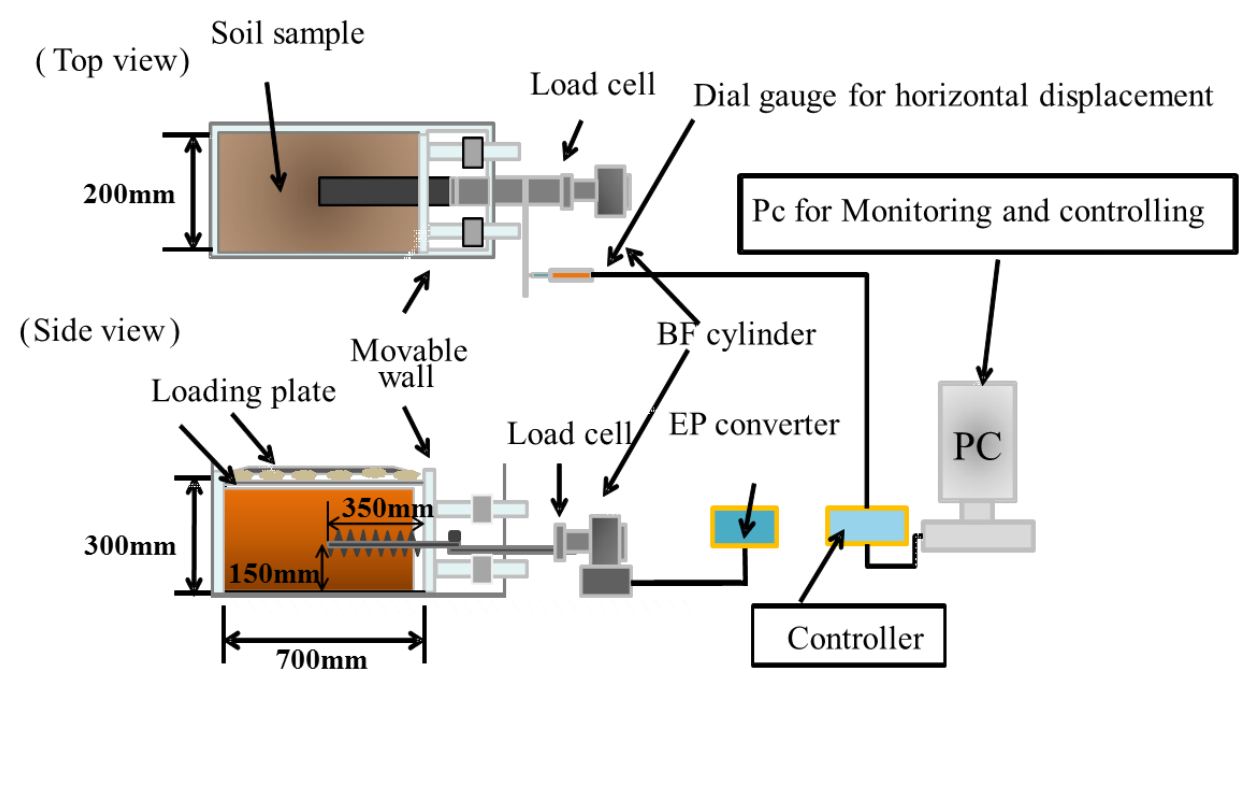

Figure 3. Outline of displacement- and/or loading-control pullout testing system.

In this study, a series of pullout tests was conducted to clarify the pullout resistance characteristics of strip and soil interfaces after displacement of a reinforced retaining wall by seismic motion. Our test was implemented according to three types of tests. In the first stage, a strip was pulled out at a constant speed from a soil layer that was compacted with varying degrees of compaction. The relationship between the maximum pullout resistance, $\tau_{\max }$, and degree of compaction, $D_{\mathrm{c}}$, was investigated based on the displacement-controlled pullout test. In the second stage, when the pullout load reached pre-yield, yield, and post-yield states, the strip was again pulled out from the soil layer under the pullout load condition. The test continued until the displacement became stable. The relationship between the loading time and displacement of the reinforced steel was established while maintaining a constant pullout load.

To identify the remaining pullout resistance after an earthquake, it was necessary to perform other pullout tests following the second stage. In the third test, when the strip's displacement reached a certain value, the test was paused and the pullout load was removed. The procedure continued by imposing another pullout load on the specimen, to examine the effect of the pullout history on the remaining pullout resistance. In our experiments, decomposed granitic soil, Masado, with $4.8 \%$ of fine particle fraction, was used as a soil sample and established at its optimum water content before the testing. The reinforcement was a metallic ribbed strip. This paper describes the evaluation of post-earthquake loading capacity of steel reinforced retaining walls based on these test results.

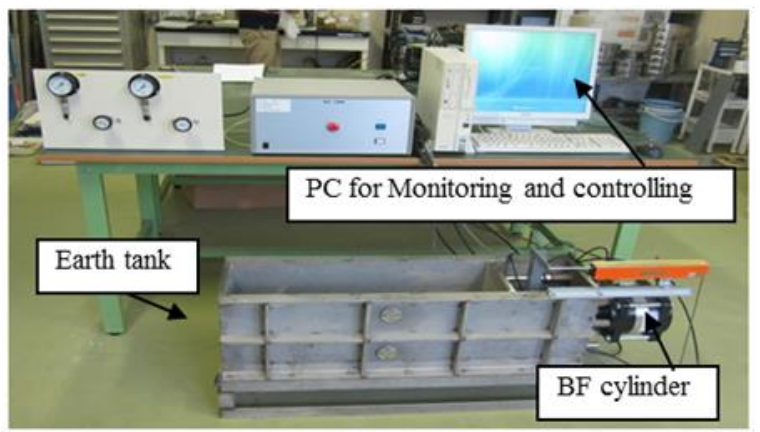

Figure 4. Overview of displacement- and/or loading-control pullout apparatus.

\section{TEST METHOD}

\subsection{Development of pullout test apparatus}

The test apparatus was designed to be able to load the strip so as to simulate the actual conditions in which pullout stress is loaded onto the strip. Figure 3 shows the side and top views of the test apparatus. Figure 4 shows overview of displacement- and/or loading-control pullout apparatus. This apparatus mainly consists of a soil tank, a facing wall, a horizontal displacement gauge, a bellofram cylinder, load cells, a strip, and air bags. The soil tank is $700-\mathrm{mm}$ long, 300-mm high, and $200-\mathrm{mm}$ wide. The horizontal displacement of the movable wall was measured from the part of the model connected to the displacement gauge. The strip with ribs was $350-\mathrm{mm}$ long, 60-mm wide, and 5-mm thick. The soil tank isn't an hermetic and pore water is permitted to drain at the bottom and the upper sides by the drainage layer and pipes. The overburden pressure was loaded by the air bag connected with the air compressor. In this test system pullout load was adjusted by the EP converter which controls the air pressure from the displacement at the certain constant rate. So the reinforced steel strip with 
designed length placed in the soil tank could be pulled out at any speed or pullout load increment. The movable wall was fixed to reproduce the real reinforced soil wall structure, moreover the boundary friction of soil tank was suppressed so as not to have influence to the pullout behaviour by applying Teflon or the grease to the interface of each parts.

In this study, the pullout tests were carried out to clarify whether the compaction degree or the pullout history affects the behaviour of pullout resistance of strip in the static test.

\subsection{Soil sample and reinforcement}

The used soil sample was Masado which was collected in Ube city. The physical characteristics of the soil sample is shown in Table 1. Figure 5 shows the compaction curve of the sample. The fine grain content ratio, $F_{\mathrm{c}}$, of the soil sample is $4.8 \%$, less than the application standard of $25 \%$ according to the manual for steel strip reinforced retaining wall (PWRC, 2003). The detailed dimension of the reinforcement as welding structural steel materials is shown in Figure 6 and Figure 7.

Table 1. Physical property of used soil sample.

\begin{tabular}{llll}
\hline $\begin{array}{l}\text { Density of soil } \\
\text { particle }\left(\mathrm{g} / \mathrm{cm}^{3}\right)\end{array}$ & $\begin{array}{l}\text { Gravel } \\
\text { fraction }(\%)\end{array}$ & $\begin{array}{l}\text { Sand fraction } \\
(\%)\end{array}$ & $\begin{array}{l}\text { Fine particle } \\
\text { fraction }(\%)\end{array}$ \\
\hline 2.61 & 38.8 & 56.4 & 4.8 \\
\hline
\end{tabular}

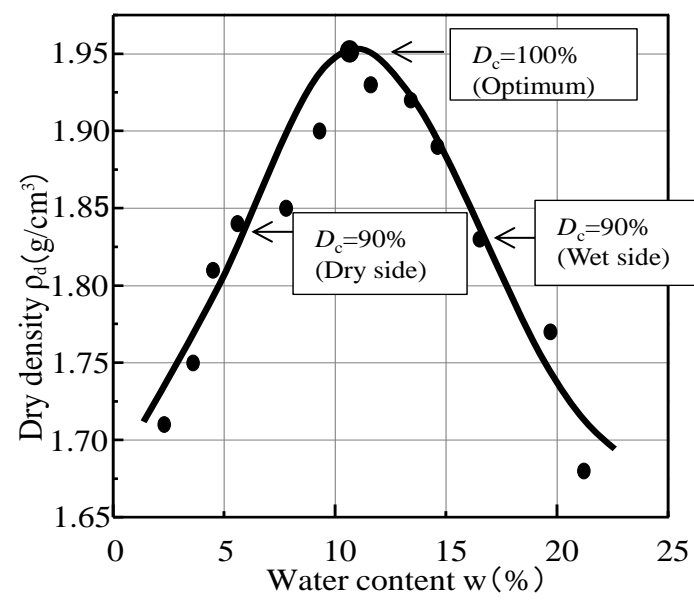

Figure 5. Compaction curve of Masado

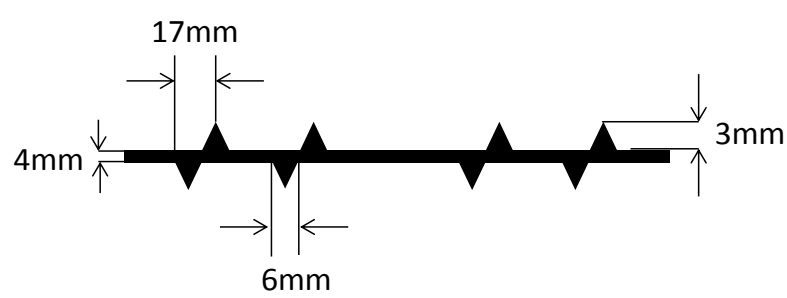

Figure 6. Shape and dimensions of steel strip used.

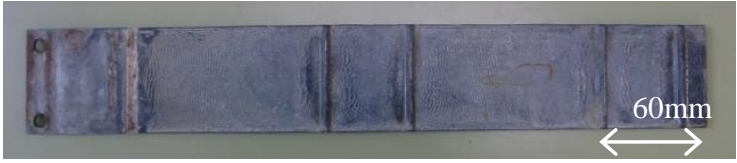

Figure 7. Overview of steel strip.
Table 2. Test conditions.

\begin{tabular}{lll}
\hline Test No. & $\begin{array}{l}\text { Degree of compaction, } \\
D_{c}(\%)\end{array}$ & $\begin{array}{l}\text { Overburden pressure, } \\
\sigma_{\mathrm{v}}\left(\mathrm{kN} / \mathrm{m}^{2}\right)\end{array}$ \\
\hline $1-1$ & 86 (Dry side) & 0 \\
$1-2$ & 92 (Optimum) & 0 \\
$1-3$ & 84 (Wet side) & 0 \\
\hline $2-1$ & 87 (Dry side) & 40 \\
$2-2$ & 91 (Optimum) & 40 \\
$2-3$ & 84 (Wet side) & 40 \\
\hline $3-1$ & 86 (Dry side) & 60 \\
$3-2$ & 92 (Optimum) & 60 \\
$3-3$ & 86 (Wet side) & 60 \\
\hline $4-1$ & 86 (Dry side) & 80 \\
$4-2$ & 92 (Optimum) & 80 \\
$4-3$ & 83 (Wet side) & 80 \\
\hline
\end{tabular}

\subsection{Test procedure}

In the pullout test, a drainage layer of unwoven cloth and filter paper was placed on the bottom of the soil tank and the retaining wall was fixed to its original position. The soil sample was mixed with water at target water contents. Next, the soil tank was filled with the soil sample in 10 divided layers. A rammer, $4 \mathrm{~kg}$ in weight and $40 \mathrm{~cm}$ in drop height, was used for tamping 15 times per layer. When the soil sample in the soil tank reached a height of $150 \mathrm{~mm}$ from the bottom, the strip was installed in the soil tank. After the soil tank was filled to the top with the soil sample, a drainage layer was set on the smoothed top surface of the soil. The overburden pressure, $\sigma_{\mathrm{v}}$, was applied on the top surface by pressurized air bags. The test procedure was initiated when the pullout speed or load was adjusted at designed values. In the case of the displacement-controlled pullout test, it was considered to be finished when the predetermined pullout displacement was attained. In the displacement- and loading-controlled pullout tests, when the pullout load reached a predetermined value, the loading method was changed from displacement controlled condition to pullout load condition. In both pullout tests, the pullout displacement, $\Delta L$, and pullout load, $T$, were measured simultaneously. The pullout resistance, $\tau$, was calculated as the pullout load divided by the total cross-sectional areas of the upper and lower parts of the strip. The decrease in contact areas of the strip during the pullout test was considered to calculate pullout resistance.

\section{RESULTS AND DISCUSSION}

\subsection{Relationship between pullout resistance and degree of compaction in displacement-controlled pullout test}

First, we examined the relationship between the pullout resistance and the degree of compaction in the displacement-controlled test. Table 2 lists test cases under the displacement-controlled condition. Figures 8 (a) to (d) show the relationships between displacement, $\Delta L$, and pullout resistance, $\tau$, in the case of the 


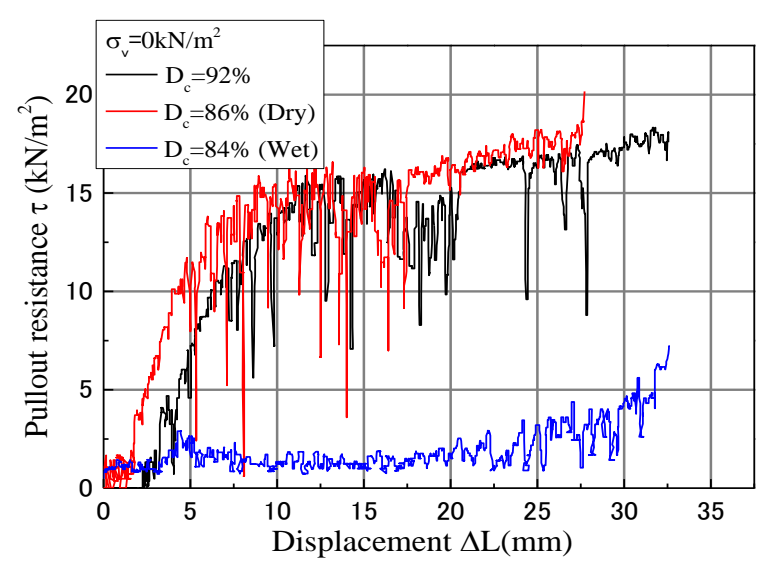

(a) In case of $\sigma_{\mathrm{v}}=0 \mathrm{kN} / \mathrm{m}^{2}$

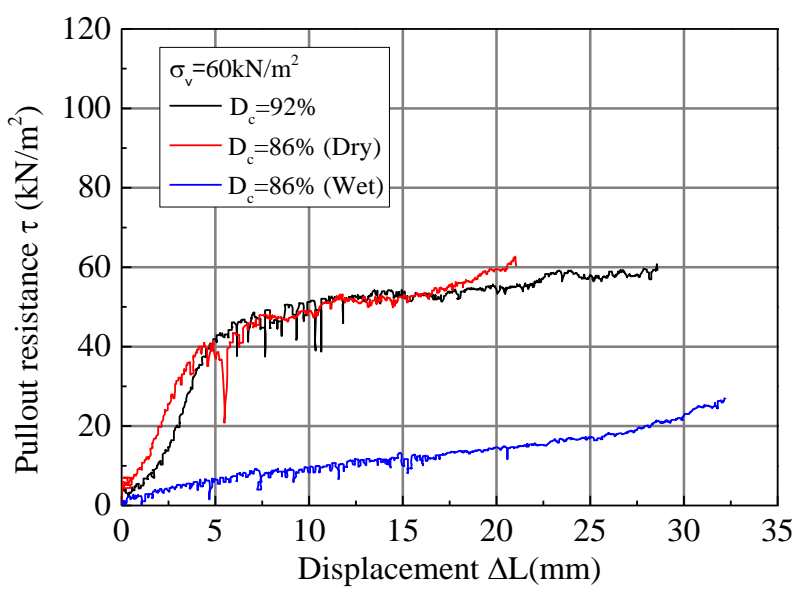

(c) In case of $\sigma_{\mathrm{v}}=60 \mathrm{kN} / \mathrm{m}^{2}$

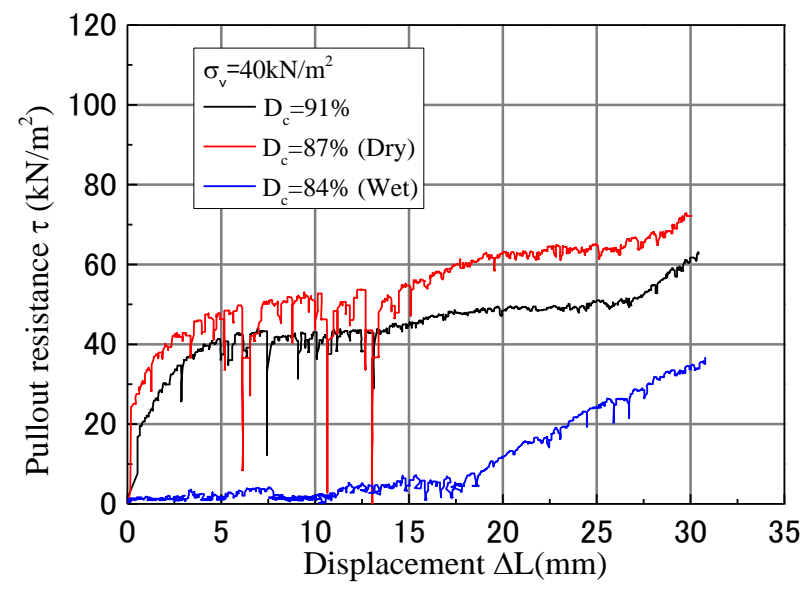

(b) In case of $\sigma_{\mathrm{v}}=40 \mathrm{kN} / \mathrm{m}^{2}$

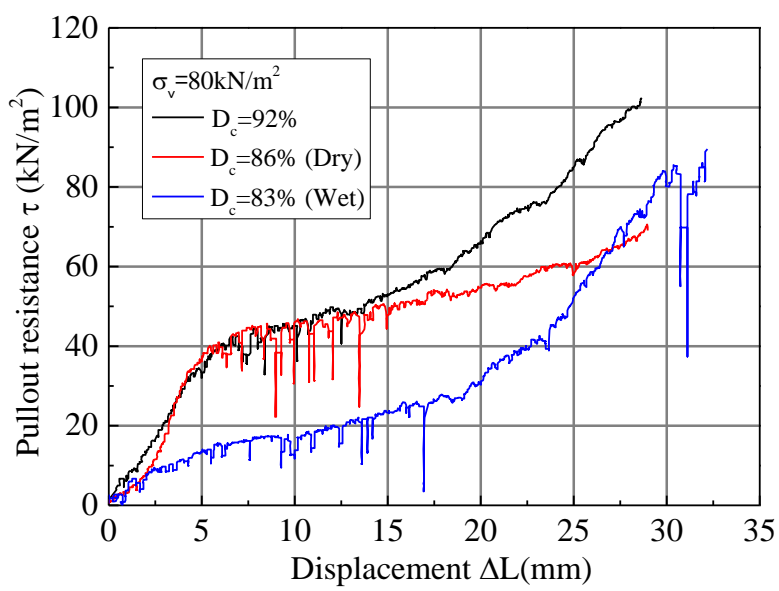

(d) In case of $\sigma_{\mathrm{v}}=80 \mathrm{kN} / \mathrm{m}^{2}$

Figure 8. Relationship between pullout resistance and displacement under different overburden pressures.

displacement-controlled tests. The fluctuations shown in the relation between $\Delta L$ and $\tau$ were attributed to the reduction of air pressure in the Bellofram cylinder to ensure a constant displacement rate $(1.0 \mathrm{~mm} / \mathrm{min})$. As shown in Figure 8 (a), in the case of $\sigma_{\mathrm{v}}=0 \mathrm{kN} / \mathrm{m}^{2}$, there was a slight difference in pullout resistance between $D_{\text {c }}$ $=86 \%$ and $D_{\mathrm{c}}=92 \%$, whereas the pullout resistance with $D_{\text {c }}=84 \%$ (wet side) represented a relatively low measured value. In the case of $\sigma_{\mathrm{v}}=40 \mathrm{kN} / \mathrm{m}^{2}$, the pullout resistance with $D_{\mathrm{c}}=91 \%$ and $87 \%$ (wet side) increased because of the dependency of confining pressure, augmented with the increased pull displacement for the three cases. In the case of $\sigma_{\mathrm{v}}=60 \mathrm{kN} / \mathrm{m}^{2}$, as shown in Figure 8 (c), the pullout resistance values of $D_{\mathrm{c}}=92 \%$ and $D_{\mathrm{c}}=86 \%$ (wet side) were almost the same as in the case of $\sigma_{\mathrm{v}}=40 \mathrm{kN} / \mathrm{m}^{2}$. Additionally, the influence of the change in confining pressure was not recognized in the pullout behaviour. The pullout resistance in $D_{\mathrm{c}}=86 \%$ (wet side) increased gradually compared with the case of $\sigma_{\mathrm{v}}=40 \mathrm{kN} / \mathrm{m}^{2}$. In the case of $\sigma_{\mathrm{v}}=80 \mathrm{kN} / \mathrm{m}^{2}$, as shown in Figure. $8(\mathrm{~d})$, the pullout resistance with $D_{\mathrm{c}}=92 \%$ and
$83 \%$ (wet side) increased rapidly when the displacement reached $15 \mathrm{~mm}$ and $20 \mathrm{~mm}$, respectively. The same tendency was not clear in $D_{\mathrm{c}}=86 \%$ (dry side).

The pullout resistance of the wet side decreased in comparison with that of the dry side at the same degree of compaction for each restriction pressure. This was considered to be caused by the reduction of effective

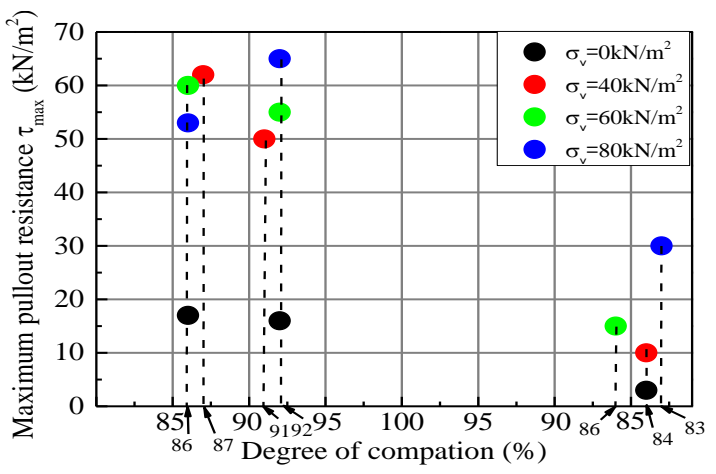

Figure 9. Change of maximum pullout resistance with degree of compaction under different overburden pressures. 
vertical pressure applied to the reinforcement, resulting from the increased degree of saturation. We considered that the excess pore water pressure in the soil tank was hardly generated because of high permeability of the soil sample. Further, the influence of water on frictional resistance is necessary to be considered. Figure 9 shows the relationship between $\tau_{\max }$ and $D_{\mathrm{c}}$. The pullout resistance attained maximum value at degrees of compaction of $92 \%$ and $87 \%$ (dry side). It also remarkably decreased at $D_{\mathrm{c}}=85 \%$ (wet side).

\subsection{Relationship between displacement and pullout loading time in displacement- and loading- controlled pullout tests}

Next, we examined the pullout behaviour of strips under constant pullout loading in a compacted soil layer for which a certain pullout history was given by the displacement and loading controlled tests. The relationship between the pullout load and the loading time in each displacement and loading controlled pullout test are shown in Figure 10 and Figure 11. Although the pullout load was controlled at a constant value, $T_{\max }=$ $0.28 \mathrm{kN}$ and $T_{1 / 2}=0.26 \mathrm{kN}$, the pullout displacement increased by $6 \mathrm{~mm}$ and $3 \mathrm{~mm}$. Here, $T_{\max }$ is the value of yield pullout load and $T_{1 / 2}$ is a certain value before the yield value. However, the displacement rapidly increased by $12 \mathrm{~mm}$ under $T_{\text {res }}=0.37 \mathrm{kN}$. $T_{\text {res }}$ is defined as a residual value in the relation between the pullout load and displacement. The pullout resistance was not exerted because a slip surface may be formed in the residual state.

\subsection{Reduction of pullout resistance of soil caused by pullout history}

As previously described, a reinforced soil wall may be subjected to external forces, such as an inertial force caused by an earthquake, causing the possibility that the pullout resistance between the backfill material and the reinforcement may be reduced or lost. In such a case, it is important to clarify how much pullout resistance remains. Hence, in the intermediate stage of the test procedure, the pullout load was stopped during a designated time period. After a pause, the strip was pulled out again to investigate the effect of the pullout history on the pullout resistance. Another soil pullout test apparatus was used for this experiment, as shown in Figure 12. The sample was tamped with a rammer until the degree of compaction, $D_{\mathrm{c}}$, reached a value of over 90\%. The following normal pullout test was conducted with pullout displacement speed $v=1 \mathrm{~mm} / \mathrm{min}$, then stopped at several points of $\Delta L=2 \mathrm{~mm}$ and $50 \mathrm{~mm}$. Next, the test restarted. Figure 13 shows the test results. Other data for sand (Chiba sand), which were tested for another purpose, are plotted in this figure. The behaviour of Masado is very similar to that of Chiba sand. Accordingly, the pullout behaviour of the strip was not significantly affected by the previous pullout. The pullout resistance depended on the total amount of

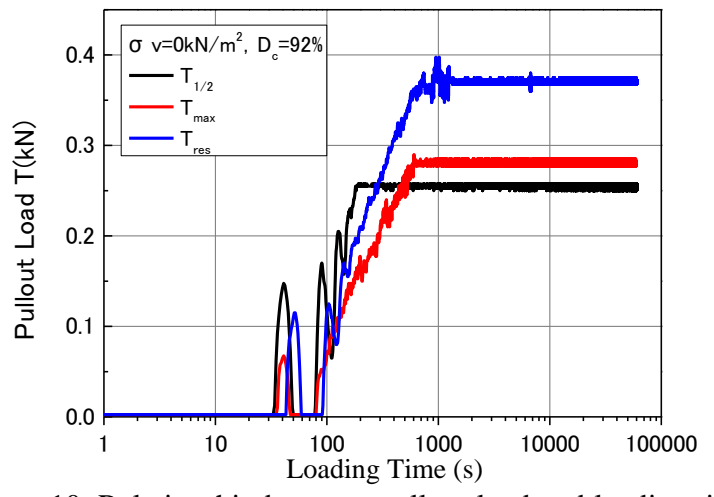

Figure 10. Relationship between pullout load and loading time in the case of $\sigma_{\mathrm{V}}=0 \mathrm{kN} / \mathrm{m}^{2}$ and $D_{\mathrm{c}}=92 \%$.

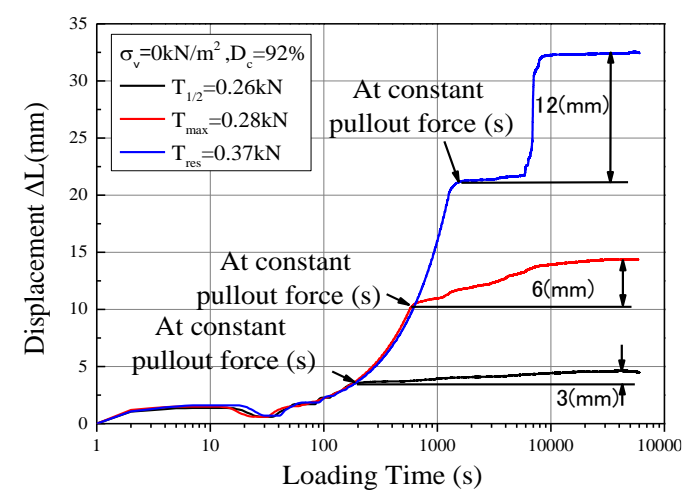

Figure 11. Relationship between pullout load and loading time in the case of $\sigma_{\mathrm{v}}=0 \mathrm{kN} / \mathrm{m}^{2}$ and $D_{\mathrm{c}}=92 \%$.

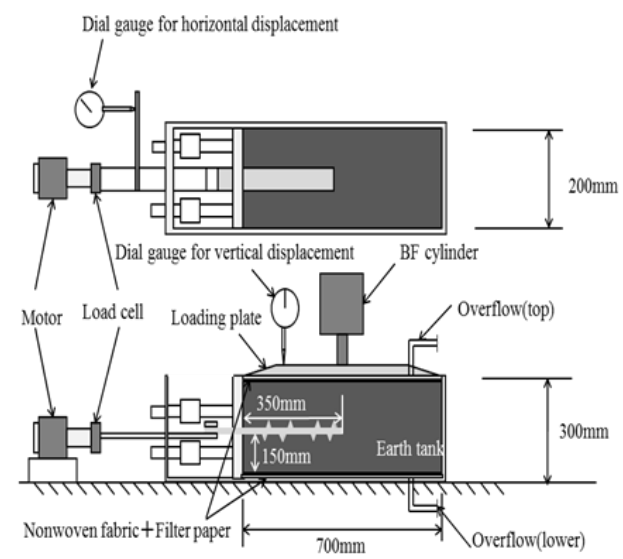

Figure 12. Schematic diagram of displacement-control pullout test apparatus (Tasaka et al., 2010).

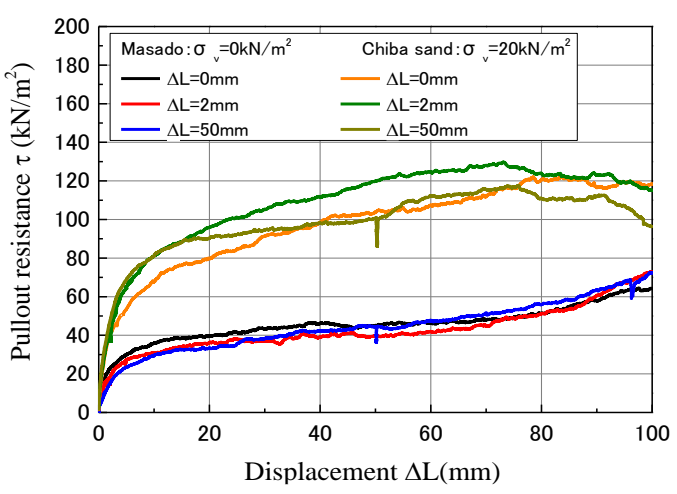

Figure 13. Pullout behavior of compacted sands subjected to pullout histories. 
pullout displacement.

\section{CONCLUSIONS}

In this study, we examine the post-earthquake loading capacity of a reinforced retaining wall to evaluate the safety, stability, and availability of damaged walls. For this purpose, we developed a novel pullout test apparatus for a compacted soil layer under displacement and/or loading controlled condition. The following conclusions were deduced from the test results on highly compacted soil:

1) In the displacement-controlled pullout test, the maximum pullout resistance of the strip from the compacted soil increased with the degree of compaction on the dry side of the optimum water content. On the other hand, when the degree of compaction was about $85 \%$ on the wet side of the optimum water content, the maximum pullout resistance was low as compared with the same compaction on the dry side.

2) When the pullout load did not exceed peak value in the relation between the pullout resistance and the displacement, the increment of pullout displacement developing under the constant loading condition was only 3 to $6 \mathrm{~mm}$. This means that the facing wall barely displaced under such the condition.

3) The pullout behaviour of strip was not significantly affected by the previous pullout history. The pullout resistance depends on the total amount of pullout displacement.

4) Unless the pullout load did not surpass peak or yield values in the relation between pullout load and displacement, even after the earthquake, the reinforced retaining wall maintained its loading capacity to some extent.

\section{REFERENCES}

1) Public Works Research Center (2003): Design Method, Construction Manual and Specifications for Steel Strip Reinforced Retaining Walls (third ed.), Public Works Research Center, Tsukuba, Ibaraki, Japan (in Japanese).

2) Sahara, K. (2012): Investigation of damage to reinforced earth walls in the great east Japan earthquake and related maintenance, Proc. International Joint Symposium on Urban Geotechnics for Sustainable Development, JS-Seoul, 74-77.

3) Tasaka, Y., Suzuki, M., Yoneda, O., Shimura, N., Sugiyama, Y. (2010): Pullout resistance characteristics of reinforcement in the applied steel reinforced soil wall solidification processing soil and reinforcement length was designed, Japan Society of Civil Engineers Proceedings C, 66(3), 516-529 (in Japanese). 